\title{
Narrativas na Formação do Professor de Matemática: o caso da professora Atíria
}

\section{Narratives in Professional Development of Mathematics Teachers: teacher}

\author{
Atíria's case
}

\author{
Edna Maura Zuffi ${ }^{*}$ \\ Cláudia Flora Degrava ${ }^{* *}$ \\ Miriam Cardoso Utsumi ${ }^{* * *}$ \\ Esther Pacheco de Almeida Prado ${ }^{\text {***** }}$
}

\begin{abstract}
Resumo
Neste artigo exploraremos as potencialidades das narrativas na Educação Matemática como um modo de relatar, representar e refletir uma experiência. Particularmente, procuraremos desvelar como a construção de narrativas escritas, por uma professora em formação continuada, constituiu-se em um importante processo de desenvolvimento profissional da mesma, durante a proposição e implementação de uma metodologia investigativa de ensino de Matemática, em uma sala de aula considerada desafiadora na escola pública. Os resultados evidenciam que, com as trocas entre os pares pesquisadores, a professora inseriu novas reflexões (na ação e sobre a ação) em sua experiência pedagógica, registrando-as para ações futuras com o uso das investigações matemáticas, despertando-lhe possibilidades de outras aprendizagens, através da perspectiva de novas propostas de sequências didáticas significativas para os alunos e que sejam factíveis para as salas de aula reais e complexas que encontramos na escola pública de hoje. Consideramos que o uso de narrativas proporcionou-lhe uma formação continuada que levou em conta as questões culturais escolares mais amplas, seus saberes docentes e experiências anteriores, superando as concepções de formação clássica.
\end{abstract}

\footnotetext{
* Doutora pela Universidade de São Paulo (USP). Professora Doutora da Universidade de São Paulo (USP), Instituto de Ciências Matemáticas e de Computação (ICMC), Departamento de Matemática, São Carlos, SP, Brasil. Endereço para correspondência: Cx. Postal 668, CEP: 13560-970, São Carlos, SP, Brasil. E-mail: edna@icmc.usp.br.

${ }^{* * *}$ Mestre em Ciências pelo Mestrado Profissional em Matemática em Rede Nacional (PROFMAT). Professora da Secretaria de Estado da Educação de São Paulo, São João da Boa Vista, SP, Brasil. Endereço para correspondência: Rua Alberto Zerbeto, 179, CEP: 13872-588, São João da Boa Vista, SP, Brasil. E-mail: claudiadegrava@terra.com.br.

**** Doutora pela Universidade Estadual de Campinas (UNICAMP). Professora Doutora da Universidade de São Paulo/USP, Instituto de Ciências Matemáticas e de Computação (ICMC), Departamento de Matemática, São Carlos, SP, Brasil. Endereço para correspondência: Cx. Postal 668, CEP: 13560-970, São Carlos, SP, Brasil. Email: mutsumi@icmc.usp.br.

${ }_{* * * * * *}$ Doutora pela Universidade Estadual de Campinas (UNICAMP). Professora Doutora da Universidade de São Paulo/USP, Instituto de Ciências Matemáticas e de Computação (ICMC), Departamento de Matemática, São Carlos, SP, Brasil. Endereço para correspondência: Cx. Postal 668, CEP: 13560-970, São Carlos, SP, Brasil. Email: estherprado2@gmail.com.
} 
Palavras-chave: Narrativas. Formação do Professor. Investigações Matemáticas.

\begin{abstract}
This paper explores potentialities of narratives in Mathematics Education as a significant way of reporting, representing, and reflecting an experience. Particularly, we intend to reveal how the construction of written narratives by an in-service teacher has constituted an important process in her professional development, when she proposed and implemented an investigative methodology to the teaching of Mathematics, in a challenging classroom of a public school. The results show that the teacher, exchanging experiences with peer researchers, inserted new reflections on her pedagogical practices (in and over the action). Those records for future trends with mathematics investigations enhanced her potentialities of new learning, through the perspective of the proposal of new didactical sequences that can be significant to the students, and feasible to real and complex classrooms we find nowadays in public schools. We consider that the use of narratives has provided her a kind of continued education that has taken into account broader cultural scholar questions, her teaching knowledge and previous experiences, overcoming classical conceptions of teacher education.
\end{abstract}

Keywords: Narratives. Teachers’ Professional Development. Mathematical Investigations.

\title{
1 Introdução
}

Neste artigo exploraremos as potencialidades das narrativas para a Educação Matemática, como um modo de refletir, relatar e representar uma experiência, produzindo sentido ao que somos, fazemos, pensamos e dizemos. Particularmente, procuraremos desvelar como a construção de narrativas escritas, por uma professora de Matemática em formação continuada, constituiu-se em um importante processo de desenvolvimento profissional da mesma. Atentar-nos-emos com mais profundidade sobre a narrativa como modo de estudar/investigar a experiência, ou seja, levaremos em consideração a perspectiva e interpretação de um de seus participantes. No caso, tomaremos em conta a experiência vivida pela professora em questão, no processo de proposição e implementação de uma metodologia investigativa de ensino de Matemática, em uma sala de aula considerada desafiadora, na escola pública em que atuava. Alguns autores como Galvão (2005), distinguem as narrativas como método de investigação, método de análise ou relato de investigação. Este último caso

\footnotetext{
pressupõe a escolha do que parece ser um discurso claro e coerente para que a história tenha sentido e credibilidade para quem lê. Tratando-se de um texto científico e não apenas literário, implica o recurso a normas de escrita, simultaneamente reveladoras dos dados de uma investigação e agradáveis para que o texto seja lido com agrado. (GALVÃO, 2005, p. 342).
}

Freitas e Fiorentini (2007, p. 66) argumentam que as análises narrativas "coletam descrições de eventos e de outros acontecimentos e geram uma narrativa como produto da pesquisa", permitindo ao pesquisador uma compreensão mais orgânica e histórica do processo de vir a ser e de desenvolver-se professor. A narrativa oferece àquele que narra e/ou investiga 
uma chance de pensar com mais profundidade, produzindo e sistematizando lembranças que por vezes tendem a ser esquecidas.

O foco deste artigo está, portanto, no relato de investigação, ou uma análise narrativa da professora Atíria, ao constituir-se como processo de reflexão pedagógica e de formação profissional. É claro que, para formular-se, o presente texto também apresenta características de uma narrativa, visto que se reporta àquelas produzidas pela professora-pesquisadora. Entretanto, consideramos que não é propriamente uma análise dessa narrativa como um discurso, mas de como ela foi se constituindo como processo, durante a aplicação da nova metodologia de ensino proposta pela professora-pesquisadora a seus alunos, com as discussões realizadas nas reuniões com a formadora da universidade, para explicitação e tomada de consciência da cultura da escola, e das reflexões que se seguiam. Poderíamos chamá-lo (o presente artigo) de uma metanarrativa, no sentido de que narra o processo de constituição da narrativa da professora-pesquisadora e as consequências do mesmo para seu desenvolvimento profissional.

Nos últimos anos, várias experiências com o uso de escrita de narrativas na Educação Matemática podem ser destacadas em nosso país. Por exemplo, Garnica (2010) faz um ensaio sobre a potencialidade de análise de fotografias dos antigos Grupos Escolares, extintos desde a década de 1970, para constituir narrativas que sirvam como fontes para estudos sobre as práticas e sobre a história da Educação Matemática no Brasil.

Uma experiência significativa com o uso de narrativas para a formação de professores foi realizada na Faculdade de Educação da UNICAMP (FREITAS; FIORENTINI, 2007, p. 65) em um curso de especialização, onde os docentes-alunos desenvolveram projetos de inovação curricular em suas classes. Essas narrativas foram objeto de reflexão e sistematização por um grupo de pesquisa-ação formado pelos autores e por dois professores formadores daquela universidade, gerando uma publicação (FIORENTINI; MIORIM, 2001). Posteriormente, professores do Grupo de Sábado (GdS) dessa instituição, tendo em vista seus interesses e necessidades, passaram a desenvolver experiências alternativas para o ensino de Matemática, as quais têm sido relatadas em narrativas escritas e publicadas.

Um exemplo de análise de narrativas orais e escritas por professores escolares pode ser encontrado no artigo de Cezari e Grando (2008), relativo a uma pesquisa que se inseriu no âmbito do Projeto de Melhoria do Ensino Público. A partir de um trabalho colaborativo com os professores de uma escola pública municipal, foram produzidas narrativas a fim de desvelar as representações de infância e juventude na cultura escolar. As autoras, ao 
analisarem tais narrativas, identificaram uma cultura de aula de Matemática presente na formação escolar dos professores que ensinam Matemática no primeiro e segundo ciclos do Ensino Fundamental. O objetivo da pesquisa foi investigar como essa cultura de aula de Matemática vinha sendo produzida na formação desses professores e (re)produzida nas suas práticas docentes. A análise preliminar de tais narrativas permitiu-lhes concluir que o modelo de aula de Matemática presente na cultura escolar valoriza a memorização e a repetição na aprendizagem matemática; que se prioriza a técnica, a memorização e o excesso de formalismo pela linguagem e que os professores acabam reproduzindo, em suas práticas, valores, crenças e representações quanto à Matemática e seu ensino, presentes na sua própria formação escolar.

Assim, segundo Larrosa (1996), a experiência formativa expressa através das narrativas seria como algo a que devemos atribuir um sentido em relação a nós mesmos. A experiência iria se constituindo num corpo de conhecimentos que conduziria o sujeito a encontrar conexões com um futuro que ainda estaria em aberto e o passado que ainda estaria vigente.

Para Freitas e Fiorentini (2007), as experiências em sala de aula e em um ambiente de pesquisa podem ilustrar o potencial da narrativa para o ensino e a aprendizagem da Matemática. Elas podem dar sentido a uma experiência educativa e as salas de aula dessa disciplina podem ser vistas como uma prática social complexa, em que professores e alunos estão tentando compreender e construir significados.

Também Cândido (2001) pesquisou a importância da utilização de diferentes recursos de comunicação no ensino e aprendizagem de Matemática, destacando a oralidade, as representações pictóricas e a escrita como modos de expressão das ideias matemáticas. As narrativas referem-se a um determinado tempo (trama) e lugar (cenário), gerando interpretações e significações que estão estreitamente ligadas às suas experiências passadas, atuais e futuras. Como também destacado por Freitas e Fiorentini (2007), o professor, ao narrar de maneira reflexiva suas experiências aos outros, aprende e ensina. Aprende, porque organiza suas ideias, sistematiza suas experiências, produz sentido a elas e, portanto, novos aprendizados para si. Ensina outros colegas que têm contatos com essa narrativa e que podem (re)significar seus próprios saberes e experiências. Disso inferimos que, ao mesmo tempo em que ele organiza suas ideias, reconstrói sua experiência numa autoanálise que lhe cria novas compreensões sobre sua prática. 
Ainda, dentre as estratégias formativas destacadas por Alarcão (2003, p. 54), as narrativas vêm ocupando um lugar de destaque nas pesquisas sobre formação de professores. Estas, quando utilizadas no grupo de trabalho coletivo, possibilitam que os professores "partilhem as suas narrativas, contem as suas histórias, as abram à reconstrução, desconstrução e significação, as ofereçam aos outros colegas que [...] as ouvem ou lêem, sobre elas questionam ou elaboram".

Assim, a narrativa da professora aqui desvelada, a quem chamaremos pelo pseudônimo de Atíria, buscou contar, transcrever, analisar e interpretar uma experiência que ela julgou significativa para sua mudança como profissional em processo de formação continuada.

Outros autores, como Schön (1992) e Zeichner (1993) asseveram que o desenvolvimento profissional de professores baseado em diferentes estratégias formativas deve ser concebido como um continuum e, nessa perspectiva, a reflexão do professor na e sobre sua prática é fundamental. Também Candau (2003, p. 150) argumenta que a formação continuada deve ser concebida como um trabalho de reflexividade crítica sobre as práticas de (re)construção permanente de uma identidade pessoal e profissional.

Tendo isso em vista, a constituição de práticas reflexivas através de narrativas, muitas vezes requer a necessidade de um agente externo que atua como disparador do processo, a partir da problematização de questões postas pela prática docente e que nem sempre se tornam evidentes para os que nela atuam. Esse agente externo teria, ainda, o papel de articulador entre as questões da prática e as teorias da educação.

Como também assevera Pimenta (2002), a teoria tem importância fundamental na formação do professor, pois provê os sujeitos de variados pontos de vista para uma ação contextualizada e oferece perspectivas de análise relativas aos contextos históricos, sociais, culturais, organizacionais e de si próprios como profissionais.

No caso de formação aqui relatado, a escrita das narrativas se deu para a elaboração de uma dissertação de mestrado, dentro de um programa de formação profissional, a partir da parceria constituída entre a professora-pesquisadora Atíria e a formadora da universidade (orientadora do projeto de formação). Essa escrita mostrou-se muito relevante para a organização de informações e para a compreensão de si mesma, durante o processo vivenciado por Atíria, em sua nova experiência com atividades de ensino investigativas, para a compreensão de seus alunos e da construção do conhecimento matemático gerado em sala de aula, a partir dessa vivência. 


\section{A pesquisa e a coletividade escolar envolvida}

Neste artigo, relatamos sobre como se deu a inserção da escrita narrativa no contexto de formação de uma professora de escola pública (Atíria), visando, também, compreender a dificuldade dos professores de Matemática em colocar no papel suas reflexões e seus pensamentos.

Ao longo do processo aqui trazido, verificamos a necessidade de uma orientação contínua e de trocas de experiência com o formador da universidade, sem as quais, uma coletividade de pesquisa dificilmente poderia ter sido idealizada pela professora em questão. Neste sentido, destacamos a importância da formação continuada do professor em instâncias institucionalizadas de saberes, para ajudá-lo a organizar suas reflexões de forma que se tornem compreensíveis para ele e para os outros colegas de profissão, compartilhando narrativas que sejam significativas também para a ação de outros agentes educacionais de sua comunidade escolar.

Nossa intenção, com este texto, é compartilhar o processo de construção de narrativas de uma professora de Matemática, ao fazer uso de metodologias investigativas para o ensino dessa disciplina, numa realidade de escola pública do Ensino Básico brasileiro, em uma sala de aula considerada "desafiadora" para a escola e para a própria docente. Acreditamos que tal processo poderá inspirar outros professores-pesquisadores e outros investigadores que queiram fazer uso de tais metodologias, ou mesmo para a construção de reflexões documentadas sobre a própria prática.

No nosso caso, a natureza do objeto de estudo da professora-pesquisadora exigia uma imersão no ambiente escolar e, além disso, respeito e valorização das perspectivas de mundo da mesma. Isto demandou um processo fortemente interativo entre o pesquisador e os participantes da coletividade escolar, que se constituíram da professora em formação e seus alunos do sétimo ano do Ensino Fundamental de uma escola pública da rede estadual, em um município do interior de São Paulo. Portanto, a abordagem qualitativa e interpretativa de pesquisa configurou-se como a mais apropriada para este caso (ANDRÉ, 1995).

Ressaltamos que a dificuldade da validação desse tipo de análise narrativa, segundo Riessman (1993), apresenta-se como a mesma de outros tipos de análise qualitativa, e compreende quatro processos: (i) a persuasão - o texto tem de ser coerente e plausível, de modo a se tornar convincente, com a explicitação dos suportes teóricos e admissão de modos alternativos de análise dos dados; (ii) correspondência - os textos devem ser construídos com 
os comentários dos participantes no estudo, após leitura de todos os documentos produzidos (entrevistas transcritas, cartas e outros textos interpretativos), (iii) coerência- o investigador tem de estar atento aos objetivos que o narrador quer atingir com a história que conta, ao local onde se passa a ação e temática que é analisada; e (iv) utilização pragmática da narrativa (um estudo particular pode constituir a base de trabalhos posteriores, assentando-se no fornecimento máximo de informação relativamente à coleta de dados e respectiva interpretação).

A professora Atíria desenvolveu suas narrativas em dois momentos: de início, ela anotava o que ia propondo dentro da nova metodologia de ensino de Matemática para seus alunos (as atividades matemáticas investigativas) e as dificuldades que iam ocorrendo, assim como os ajustes de percursos que foram sendo necessários em seus planejamentos iniciais para cada etapa; posteriormente, ela usou essas anotações para constituir as narrativas propriamente ditas, com o intuito de contar sua experiência e compartilhá-la com outros leitores, reorganizando-as em sua dissertação de mestrado, procurando atender aos critérios de persuasão e coerência em seu texto. Estes últimos foram os momentos que demandaram maior reelaboração e reflexões por parte da professora-pesquisadora e uma interação intensa com a formadora na universidade.

Assim, este trabalho reporta-se a dois processos investigativos: a pesquisa na sala de aula da professora Atíria, com a sua busca de conhecimentos sobre a metodologia de ensino de Matemática através de investigações (PONTE; BROCARDO; OLIVEIRA, 2003) e sua aplicação nessa sala, seguida de uma outra pesquisa, sobre o desenvolvimento profissional dessa professora, ao constituir as narrativas sobre suas experiências didáticas com esse novo conhecimento. Ambas as estratégias eram desconhecidas por ela: as metodologias investigativas para o ensino da Matemática, com modificação direta de sua prática, e também a construção de análises narrativas para a reflexão na e sobre a ação.

Nossa análise da narrativa da professora Atíria baseia-se na proposta de análise de Freitas e Fiorentini (2007), segundo a qual a primeira dimensão para caracterizar os sujeitos investigados e o ambiente escolar seria a "temporalidade", envolvendo passado, presente e futuro. A segunda dimensão corresponderia às interações "pessoais e sociais" e a terceira, ao "lugar", o cenário onde acontece a trama a ser narrada. Um outro complemento deste modelo de análise foi o estudo das recorrências que examinam as relações semânticas entre frases, de modo a estudar as estruturas de informação do texto em termos de inferências do escritor e do leitor, geralmente assinaladas por palavras-chave (GALVÃO, 2005, p. 333-334). 
Já como parte de sua narrativa, a professora Atíria caracteriza a escola ${ }^{1}$ em que a experiência narrada ocorreu, e também seus alunos:

Os sujeitos investigados correspondem a uma turma de sétimo ano de uma escola estadual, da cidade de São João da Boa Vista, interior de São Paulo, em que esta professora-pesquisadora atua como docente, desde o início do ano de 2012. [...] O funcionamento (da escola) se dá nos períodos da manhã e tarde. A maior parte dos alunos são moradores de um bairro carente, que enfrenta muitos problemas de violência e drogas, problemas estes que se refletem no comportamento de muitos [...]. Neste sentido, a escola carrega sérios desafios e enfrenta preconceitos [...] Atende também alunos de zona rural, que corresponde a $21 \%$ do total. Ainda por conta da localização ou condição financeira, há muita dificuldade em se trabalhar com pesquisas dos estudantes sobre os conteúdos escolares, uma vez que muitos não têm acesso à internet em casa e usá-la apenas no laboratório de informática da escola não é suficiente.,

Após descrever o espaço físico da escola, Atíria complementa:

Em relação aos recursos didáticos, apenas duas salas de aulas contém lousa branca [...]; as demais têm lousa convencional e todas possuem mais uma lousa na parede lateral, que não é usada. No pavimento superior, todas as salas possuem TV e o único aparelho de DVD deve ser agendado pelos professores. Também possui um retroprojetor, montado na sala de informática, que contém 10 computadores para uso dos alunos e um notebook conectado ao retroprojetor. Os professores reclamam que há uma dificuldade de se trabalhar vídeos e aulas diferenciadas neste ambiente, pois muitas vezes o notebook não abre os documentos ou está em manutenção. [...] A escola também possui uma biblioteca pequena, mas bem montada [...]. Ela, porém, é pouco usada; os alunos não se interessam muito e os professores não têm o costume de levá-los até lá.

A seguir, a professora passa a descrever sua visão do sistema organizacional e do projeto pedagógico da escola:

O planejamento escolar, que ocorre no início de cada ano, prevê avaliações diagnósticas e contínuas [...]. Além das avalições diagnósticas, os alunos participam de avaliações externas, como o SARESP, em nível estadual, e a Prova Brasil, em nível nacional. [...] A equipe gestora apoia os docentes na realização das atividades, embora, muitas vezes, não haja entrosamento e entendimento suficiente no processo de ensino e aprendizagem.

Posteriormente, Atíria narra sobre o processo de escolha da sala de aula em que desenvolveu sua experiência didática diferenciada:

A escolha da classe e dos alunos envolvidos neste trabalho se deu perante algumas características apresentadas, [...] sendo elas de caráter educacional $e$ comportamental. No total são 34 estudantes, sendo 18 meninos e 16 meninas. A média de idade é 12 anos e cerca de um terço deles são moradores de área rural. No geral,

\footnotetext{
${ }^{1}$ A escrita da professora será reproduzida no estilo formal que ela utilizou para compor as narrativas como parte de sua dissertação de mestrado.
} 
são alunos indisciplinados. O grupo iniciou o ano letivo com pouca, ou quase nenhuma, noção de posicionamento perante a aula: por exemplo, os alunos não traziam materiais escolares, não abriam seus cadernos, demoravam a se engajar nas atividades. Hoje, após vários meses de convívio, já conseguem se organizar melhor e participar da rotina diária. Porém, antes da realização desta pesquisa, a concentração ainda deixava a desejar, para a maioria deles. Dois motivos que chamaram a atenção no grupo, os quais fizeram escolhê-lo para a atividade investigativa, foram: a aprendizagem e sua visão de mundo. Mesmo com toda a indisciplina e falta de controle, os alunos demonstravam uma vontade muito grande de aprender, e quando se mobilizavam, apresentavam rendimento satisfatório nas atividades propostas, tornando-se ativos e participativos. [...] Em relação ao segundo motivo, em algumas rodas de conversa dentro da sala de aula, causaram espanto nesta professora com a incompreensão que possuem em relação ao sistema monetário. [...] Disseram abertamente do desejo de se relacionarem, terem filhos $e$ que viverão bem com apenas alguns reais. Isto motivou a pesquisa e a escolhê-los, a fim de propor atividades que os ajudassem a desenvolver o raciocínio crítico [...].

Em seguida, Atíria questiona suas práticas anteriores e justifica sua escolha pela metodologia de ensino com investigações matemáticas, que para ela era "nova", até então:

Podemos questionar: ser professor significa debitar matéria, usar lousa, projetor, transmitir informação? Ou ser professor significa promover a aprendizagem e avaliar resultados? Após a aplicação da Avaliação de Matemática para o $7^{\circ}$ ano do Ensino Fundamental, do Estado de São Paulo (SÃO PAULO, 2012), [...] verificou-se que os alunos [...] não apresentavam o domínio em resolver situações problemas envolvendo cálculos de porcentagem. Além disso, 50\% apresentaram dificuldades de converter os dados de uma tabela para um gráfico de setores. [...] A partir dessa análise diagnóstica, constatou-se que tais conteúdos seriam interessantes para serem desenvolvidos através da metodologia de investigações matemáticas, com a qual a professora-pesquisadora teve contato em seus estudos durante o mestrado profissional. Desse modo, foi planejada a sequência didática subsequente, em que os alunos do $7^{\circ}$ ano da turma escolhida deveriam explorar dados e investigar situações familiares a eles, envolvendo o conceito de porcentagem, os recursos de tabelas e gráfico. Como atividade de caráter investigativo, os alunos tinham como desafio criar a identidade da turma, retratando matematicamente, seus sonhos, personalidades $e$ expectativas de vida.

Nos dizeres anteriores, a professora-pesquisadora caracteriza também a temporalidade atual da escola pública, sujeita aos exames externos de classificação de desempenho. Além disso, expõe a novidade da metodologia que ela irá passar a usar em relação às suas práticas passadas e a situa como possibilidade real para o futuro de suas práticas pedagógicas, ao questionar o que significa "ser professor".

Nos encontros com Atíria, procuramos utilizar, sempre que possível, estratégias de desenvolvimento da capacidade de reflexão, ou simplesmente, estratégias de formação que, segundo Alarcão (2003, p. 58) são aquelas que: 
têm como objectivo tornar os professores mais competentes para analisarem as questões do seu quotidiano e para sobre elas agirem, não quedando apenas pela resolução dos problemas imediatos, mas situando-os num horizonte mais abrangente que perspectiva a sua função e a da escola na sociedade em que vivemos

Também Libâneo (2002) pondera sobre as necessidades dos professores desenvolverem simultaneamente três tipos de capacidades reflexivas: a de apropriação teórico-prática das realidades concretas da ação docente; de apropriação de metodologias de ação, procedimentos facilitadores do trabalho e de resolução de conflitos ou dificuldades da sala de aula; e de consideração dos contextos sociais, políticos e institucionais na configuração das práticas escolares.

Dessa forma, as reuniões quinzenais ou mensais entre a formadora da universidade e a professora-pesquisadora, com duração de duas a quatro horas, constituíram-se num espaço privilegiado para o autoconhecimento de ambas, mas principalmente para o conhecimento da professora em formação, com suas reflexões sobre a própria prática pedagógica e a explicitação e tomada de consciência da cultura de sua escola.

Essas reuniões eram marcadas pelo questionamento da professora-pesquisadora a respeito de suas dificuldades para ensinar e o confronto de opiniões e abordagens. Também a formadora da universidade - atuando no papel de agente externo à escola - assumia uma atitude questionadora, indicando o estudo de teorias e as possibilidades de confrontá-las com a prática efetiva na sala de aula real daquela professora.

Assim se deu a apresentação da professora aos estudos teóricos e práticos sobre o uso de atividades investigativas em aulas de Matemática (PONTE; BROCARDO; OLIVEIRA, 2003), bem como sobre a ideia de se estabelecer um novo contrato didático em sua turma (BROUSSEAU, 1986). Ela aceitou a novidade dessa metodologia de ensino e a proposta de fazer um novo contrato com seus alunos, pois estava interessada em mudar sua prática, uma vez que aquela sala lhe constituía um grande desafio, devido à indisciplina, mas também pela sua reflexão sobre a capacidade de aprendizado de seus alunos.

Saviani (2000, p. 21) enfatiza que a reflexão é provocada por um problema. No caso de Atíria, pela indisciplina e dificuldade de aprendizado do grupo. Tal reflexão se caracterizaria, segundo esse pesquisador, pelo aprofundamento da consciência da situação, acarretando um salto qualitativo que levaria à superação da dificuldade no seu nível original:

\footnotetext{
[...] quando surge o problema, ou seja, quando não sei que rumo tomar e preciso saber, quando não sei escolher e preciso saber, aí surge a existência do filosofar, aí eu começo a refletir [...]. À medida que a reflexão prossegue, as coisas começam a ficar mais claras e a resposta vai se delineando. Estrutura-se então uma orientação, princípios são estabelecidos, objetivos são definidos e a ação toma rumos novos tornando-se compreensível, fundamentada, mais coerente (SAVIANI, 2000, p. 21).
} 
As ocasiões de discussão teórica com a professora Atíria, acima relatadas, foram mais raras (quinzenais ou mensais), devido ao fato de seu curso de formação ser de natureza semipresencial, o que tornou mais remotas essas trocas pessoais. Entretanto, talvez por esse motivo, estas foram muito valorizadas pela professora e sua narrativa reflete vários momentos de discussão sobre as teorias sobre investigações matemáticas e sobre o conceito de contrato didático, como será mais detalhado no próximo item.

\section{Análise da construção das narrativas como processo de formação da professora}

Cabe esclarecer que tanto a produção de narrativas quanto o desenvolvimento de pesquisas narrativas não são práticas fáceis. Ambas demandam do narrador e/ou pesquisador um forte diálogo entre teoria e prática, ou melhor, entre a experiência particular de vida de cada um e o movimento histórico-cultural das práticas sociais das quais faz parte.

No caso do ensino de Matemática, outro fator que dificulta a construção de narrativas sobre as práticas pedagógicas é a lacuna que geralmente ocorre na formação inicial de professores, entre os conhecimentos teóricos e os pedagógicos. Esta é observada por Damico (2007, p. 30), para quem é importante que as competências matemáticas sejam desenvolvidas de forma articulada com o conhecimento pedagógico e o conhecimento de processos de investigação que possibilitem o aperfeiçoamento da prática pedagógica. Dessa forma, podemos deduzir que, como afirma Tardiff (2002), o professor ideal é aquele que domina os conhecimentos relativos à área em que atua, à disciplina e ao programa conforme consta no currículo; tem conhecimentos relativos às ciências da educação e à pedagogia e desenvolve um saber prático a partir da reflexão sobre suas experiências.

Podemos dizer que a professora-pesquisadora aqui mencionada conseguiu um bom resultado sobre isso, ao narrar sua produção da prática, relacionando-a ao estudo teórico das metodologias investigativas em Matemática e também do contrato didático, como podemos constatar nos excertos a seguir.

Com relação ao seu estudo teórico sobre as metodologias investigativas, Atíria faz uma articulação com, e uma reflexão sobre os documentos oficiais e currículos de seu sistema de ensino, quando escreve: De acordo com a Proposta Curricular do Estado de São Paulo (São Paulo, 2008b, p. 30):

A Matemática nos currículos deve constituir, em parceria com a língua materna, um recurso imprescindível para uma expressão rica, uma compreensão abrangente, uma argumentação correta, um enfrentamento assertivo de situações-problema, uma 
contextualização significativa dos temas estudados. [...] Apesar do discurso do documento citado no parágrafo anterior, pouco se nota a prática de atividades investigativas, no sentido aqui estudado, nos exemplares dos "Cadernos do Aluno" de Matemática do Ensino Fundamental. A nosso ver, [...] tal prática auxiliaria muito o desenvolvimento da autonomia dos alunos, do poder de expressar e compreender, argumentar e decidir, transpondo o concreto para o abstrato e relacionando ideias abstratas com decisões da vida diária. [...] A escolha das atividades investigativas partiu do pressuposto de que estas [...] desenvolvem os eixos norteadores de competências, presentes na Proposta Curricular do Estado de São Paulo: expressão/compreensão, argumentação/decisão e contextualização/ abstração. Mais do que nunca, desenvolvem alunos participativos, críticos, colaborativos, atuantes e autônomos. [...] Talvez pela ausência desse tipo de atividades nas práticas escolares cotidianas, a professora-pesquisadora tenha encontrado dificuldades iniciais em esclarecer e engajar os alunos na investigação. [...] Também a prática do relatório foi introduzida, uma vez que isto não era hábito dos alunos deste $7^{\circ}$ ano. [...] Houve a motivação para que os alunos buscassem aperfeiçoar cada vez mais os seus registros. [...] Os grupos receberam várias instruções e a respeito do relatório [...].

$\mathrm{O}$ excerto anterior reflete como o processo de construir narrativas escritas pela professora em formação continuada fez-lhe valorizar, nas atividades investigativas em Matemática, o registro escrito de seus alunos. Este aspecto está presente na propositura das investigações matemáticas por Ponte, Brocardo e Oliveira (2003), porém, poderia ter sido menos enfatizado pela professora, segundo observações suas, caso ela própria não estivesse vivenciando algo semelhante em seu desenvolvimento.

Sobre a relação da sua prática e a ideia teórica de contrato didático, ela observa:

O momento dos esclarecimentos iniciais, acerca do contrato didático e do relatório a ser feito, foi muito importante para o bom direcionamento da atividade. [...] Evitou-se [...] a imposição de regras e condutas, mas foi negociado um comportamento participativo nas atividades. A professora detalhou o desenvolvimento da atividade e os alunos foram informados que deveriam criar a identidade da turma, promovendo, inicialmente, a construção de um contrato didático. Formaram-se os grupos e discutiram-se maneiras de agir durante a realização das atividades. Em seguida, de posse dos relatos, os alunos socializaram as ideias chegando a uma redação coletiva do contrato acordado, mediados pela professora [...].

Atíria narrou suas percepções sobre "abalos", ou pequenos rompimentos ocorridos no

contrato, mas também sua alegria nos momentos de superação dos mesmos:

Durante as aulas, pequenos momentos de discórdia ocorreram entre os discentes, porém nada semelhante ao que já ocorrera em outras ocasiões. [...] O respeito se deu da melhor forma possível, facilitando o desenvolvimento do trabalho, o que mostra que o contrato didático negociado era cumprido na maioria do tempo. Felicitou-se a professora-pesquisadora, uma vez que era um dos objetivos de sua proposta, a melhoria do relacionamento nessa sala. [...]. Isso também favoreceu o maior engajamento dos alunos na elaboração dos raciocínios matemáticos, embora alguns ainda apresentassem maiores dificuldades que outros. $O$ contrato didático negociado - os combinados - veio a fortalecer o respeito necessário. [...] O término do ano letivo foi de grande parceria entre todos, ficando as expectativas para o futuro, diferentemente do início [...]. 
O excerto acima mostra também uma apropriação teórico-prática da realidade da sala de aula e de procedimentos de resolução de conflitos que surgem aí, como mencionado por Libâneo (2002).

A sequência didática construída pela professora Atíria inspirou-se numa atividade do Caderno do Aluno do Estado de São Paulo (São Paulo, 2008a), para o $7^{\circ}$ ano do Ensino Fundamental, porém ela foi adaptada para que tivesse um caráter de investigação matemática, no sentido proposto por Ponte, Brocardo e Oliveira (2003). Intitulou-se "Mostrando a nossa cara" e tinha como objetivos sanar as dificuldades detectadas na sala de aula com relação à interpretação de dados com porcentagens, gráficos e tabelas, e desenvolver outras competências relacionadas ao tratamento da informação, com seus alunos do $7^{\circ}$ ano.

Estes foram esclarecidos que deveriam escolher características próprias para investigar, como suas idades, seus gostos, suas atividades, a fim de criarem uma identidade da turma, retratando matematicamente seus sonhos, personalidades e expectativas de vida. Esta orientação talvez tenha limitado a possibilidade de abertura para que eles escolhessem variáveis quantitativas. A classe foi dividida em grupos de quatro ou cinco integrantes, segundo as afinidades dos estudantes.

A primeira etapa da tarefa foi dedicada à construção do contrato didático (BROUSSEAU, 1986) e, após ter orientado seus alunos sobre o caráter de uma atividade investigativa em Matemática, ficou estabelecido, por orientação da professora, como seria produzido o relatório ao final de cada aula, pelos grupos, bem como os critérios avaliativos que seriam adotados durante o processo investigativo.

$\mathrm{Na}$ segunda etapa, os alunos decidiram sobre quais questionamentos seriam feitos aos colegas, para o levantamento dos dados da turma.

A decisão sobre como fariam a coleta desses dados foi feita coletivamente na terceira etapa, a qual foi realizada no pátio da escola, com o revezamento dos grupos para entrevistarem uns aos outros (cada grupo ficou responsável por coletar dados sobre uma característica levantada na primeira etapa).

A quarta etapa compreendeu a organização desses dados, sua interpretação e os cálculos de porcentagens relativas aos mesmos, assim como a escolha dos modos de sua apresentação (os alunos decidiram-se pelas tabelas e gráficos de setores). Após essa tomada de decisão, os alunos partiram para as resoluções matemáticas para construí-los, pesquisando em livros e sempre orientados pela professora. 
A quinta etapa constituiu-se da redação coletiva de uma carta que foi entregue ao dirigente regional de ensino, na qual a turma apresentava suas características, fazendo uso das sínteses dos dados e reinterpretando suas representações matemáticas por gráficos e tabelas.

Sobre a coleta de dados, Atíria fez a seguinte reflexão:

Esta foi uma etapa muito importante [...]. Apresentou o desafio de levar os estudantes a decidirem sobre como essas informações seriam levantadas. Essa e outras dúvidas surgiram durante o processo, o que é característico das atividades de investigação, $e$ que auxilia no desenvolvimento da autonomia dos educandos para futuras tomadas de decisão. Sempre reunidos, as decisões eram tomadas e os alunos chegavam à melhor opção.

Atíria observou e registrou o processo de aquisição dos conteúdos matemáticos envolvidos na construção das tabelas e gráficos de setores, pelos alunos, refletindo sobre sua postura pedagógica diante dos erros ocorridos nesse processo, e novamente relacionando as teorias estudadas com sua prática:

Iniciou-se pela construção de tabelas, com valores numéricos para indicar a quantidade de escolhas. Percebeu-se, então, que alguns grupos precisariam reformular novamente a coleta, pois as informações não eram coerentes com o número de alunos da sala. Fez-se, então, uma análise do erro, com busca da solução. $\mathrm{Na}$ matemática, conforme Pinto (2000), o "erro" não deve ser eliminado bruscamente. Todos nós temos limitações e precisamos de estímulos e compreensão para despertar nossos interesses, e a detecção do erro é uma etapa importante para conceitos e ações.

Com relação ao processo de aquisição do conhecimento dos alunos sobre porcentagens, o excerto a seguir mostra as ações da professora como mediadora, sua compreensão sobre a aprendizagem significativa, bem como sua alegria e surpresa diante dos resultados que obteve:

Dando sequência, o momento fundamental e muito esperado foi o cálculo dos valores percentuais [...]. Sempre com função mediadora, [...] a professora atendeu a todos os grupos, encorajando-os e direcionando-os. Cabe ressaltar que nesse momento, como atividade investigativa, os alunos não tinham um caminho a ser seguido, apenas um objetivo a ser alcançado. Várias estratégias foram utilizadas e o fato de grande parte dos grupos terem feito uso da regra de três para o cálculo das porcentagens, surpreendeu positivamente a professora-pesquisadora, pois esse conteúdo (regra de três), abordado com a turma em meses anteriores à aplicação da sequência didática, não havia sido relacionado com a porcentagem. Percebeu-se também, a familiarização que possuíam a respeito de valores inteiros, tais como as quantidades correspondentes o $100 \%$, a metade e a metade da metade (50 e $25 \%$ respectivamente), dentre os dados coletados [...]. 
As reflexões de Atíria mostram também o processo de aquisição e desenvolvimento de suas capacidades reflexivas (LIBÂNEO, 2002), em particular sobre a apropriação das metodologias de ação:

Uma das vantagens das atividades investigativas pôde ser observada na diversidade de estratégias abordadas, de acordo com um entendimento real da situação. É nesse sentido que se dá a aprendizagem significativa, muitas vezes almejada e não alcançada na apresentação de modelos de problemas el ou exercícios de fixação.

Com o auxílio dos questionamentos de sua formadora, Atíria elaborou uma reflexão

sobre a avaliação da aprendizagem de seus alunos, durante o processo investigativo:

Em síntese, os registros desta etapa, evidenciaram que todos os grupos foram capazes de relacionar o conceito matemático de porcentagem com as representações em tabelas e gráficos, bem como a representação geométrica de setores e a medida de ângulos em graus. Não foi possível realizar avaliações individualizadas [...]. Porém, conforme foi observado durante o desenvolvimento desta etapa, a grande maioria dos alunos estava por dentro das ideias discutidas, pois vários desejavam auxiliar seu grupo com os registros. [...] Até mesmo alunos considerados mais fracos participaram da atividade, demonstrando ter capacidades muitas vezes não percebidas nas aulas tradicionais.

Após a aplicação da sequência didática, refletindo sobre sua própria formação, a professora escreveu ${ }^{2}$ :

Mediante o desafio de promover a aprendizagem matemática em seus alunos, após leituras sobre a metodologia investigativa e análise de diversos materiais didáticos, a professora construiu sua própria sequência didática fazendo uso de investigações. [...] Sempre em busca de novas situações de aprendizagem, a professora, provou, ao final, que a aplicação de atividades investigativas é possível em salas de aula desafiadoras [...] mas nada seria possível se não existisse, além da motivação pessoal da docente, a aquisição do conhecimento pedagógico sobre o contrato didático negociado, o qual direcionou o modo de agir dos educandos. [...] Com o desenvolvimento e a redação deste trabalho, a professora aprendeu, ainda, a refletir continuamente sobre a sua ação didático-pedagógica, com os estudos sobre a pesquisa qualitativa. É real a necessidade da flexibilização no planejamento $e$ execução das atividades, com retomadas constantes. Mediante a realização dos registros realizados pelos alunos, pôde melhor conduzir a sala nas aulas subsequentes. [...] Esta prática, não comum em aulas anteriores desta professora, auxiliou muito na condução das aulas investigativas. [...] Diferentemente das aulas tradicionais, onde os alunos são dispostos em fileiras, e o professor é o autor do processo, as atividades investigativas favorecem a mobilidade dos alunos, ora em grupos, ora em roda, dentre outras disposições, ora trocando ideias, ora pesquisando nos livros, favorecendo a fixação da atenção sobre as tarefas a serem realizadas $e$, consequentemente, a aprendizagem. As constantes devolutivas e orientações realizadas pela professora, nos registros, mostrou o benefício desta prática nas aulas,

\footnotetext{
${ }^{2}$ Como já afirmado, a professora optou por narrar formalmente, em terceira pessoa.
} 
fazendo com que os alunos analisassem os erros e buscassem por novas ações. Isso é a construção do conhecimento!

A seguir, Atíria reporta-se a seu desenvolvimento profissional, mediante os estudos teóricos realizados com Shulman (1986), sobre o conhecimento pedagógico do conteúdo:

[...] Ao aplicar esta sequência didática, a professora-pesquisadora pode dizer que houve um desenvolvimento de seu conhecimento pedagógico do conteúdo, bem como dos conhecimentos curriculares, ao interpretar a Proposta Curricular do Estado de São Paulo, à luz de uma nova ideia metodológica e de sua propositura na prática de uma sala de aula considerada desafiadora. Esse conhecimento é construído pelo professor ao ensinar. É o real conhecimento do conteúdo, que inclui, além da compreensão sobre um tópico de uma disciplina, também os procedimentos e as técnicas necessárias para se alcançar a aprendizagem, aqui entendida de modo que ocorra significativamente para os estudantes [...].

Posteriormente, a professora-pesquisadora faz uma reflexão crítica profunda sobre a ação pedagógica previamente executada, baseando-se nas discussões anteriormente realizadas com a formadora da universidade:

Sala numerosa, indisciplinada, com defasagem de aprendizagem, sem muitos recursos... Sim, a aprendizagem é possível! E através das atividades investigativas, ela se torna significativa e desenvolve a autonomia, além de beneficiar as relações interpessoais. Uma crítica que pode ser feita a este tipo de abordagem em sala de aula é que ela toma um tempo considerável para trabalhar os conteúdos matemáticos. Por esse motivo, é claro que devemos mesclar outras metodologias de ensino, cada uma com seu benefício. Como decidir? Cabe ao bom professor diagnosticar, avaliar e tomar decisões, a fim de proporcionar a aprendizagem para todos os seus alunos, mesmo que em diferentes tempos e níveis, para cada um. Porém, um suposto "gasto excessivo" de tempo [...] é compensado pelas vantagens que as investigações matemáticas proporcionam [...].

Neste último excerto, a professora Atíria deixa refletir os dilemas de muitos professores de Matemática em aceitar o uso de metodologias investigativas, ou daquelas mais ativas, devido ao tempo maior que estas envolvem para sua implantação em sala de aula, comprometendo, muitas vezes, a apresentação de vários detalhes de conteúdos, o que é comum nas metodologias mais tradicionais de ensino.

Os dilemas, de acordo com Caetano (1997, p. 194), são vivências subjetivas ou conflitos interiores entre a própria ação e o pensamento, ou entre posições de valores opostos de um mesmo curso de ação; contradições entre o pensamento e ação do professor; conflitos cognitivos e práticos, ocorridos em contextos profissionais e em relação aos quais o professor equaciona duas ou mais alternativas (de ação e/ou valoração). Em suma, o núcleo dos dilemas está na existência de divergências e na "dificuldade em tomar posições claras entre os polos 
de conflito, e sua resolução pode exigir processos de deliberação complexos, integrados e criativos".

Podemos afirmar que a professora Atíria equacionou seus dilemas quanto à adoção das metodologias investigativas, segundo sua narrativa do último trecho do excerto anterior, quando avalia os benefícios (desenvolvimento da autonomia dos discentes, melhora nas relações sociais, aprendizagem significativa) e os malefícios (tempo gasto, corte de alguns conteúdos), e sugere uma mescla, um equilíbrio no uso das diversas abordagens.

Ainda, como destacam Clandinin e Connelly (2000 apud FREITAS; FIORENTINI, 2007), na pesquisa narrativa, o pesquisador apresenta um contexto que vai além do que ele viu ou lhe foi falado diretamente, atribuindo sentido às expressões, gestos, alterações de movimentos e respiração, que delineiam a estrutura da narrativa de suas observações e suas falas. Isso também ocorreu com a professora Atíria, ao relatar um fato ocorrido após a finalização de suas atividades com as investigações matemáticas, o qual não se relacionava diretamente com a prática de ensino dessa disciplina em si, mas que foi considerado significativo para ela, na percepção de suas relações construídas com os alunos, e não necessariamente explicitadas na sala de aula:

Um fato marcante ocorreu, logo após o término da aplicação, fora da sala de aula. Uma aluna, que nesse dia apresentou comportamento inadequado para um ambiente escolar, quando todos temiam por seus atos, aceitou apenas a aproximação desta professora-pesquisadora, contando suas dificuldades e desesperos do momento de tais atos inapropriados. Isto evidenciou, mais uma vez, como as relações interpessoais foram fortalecidas e como o processo investigativo propiciou confiança desta aluna para com a professora-pesquisadora.

Freitas e Fiorentini (2007) argumentam que aquilo que os pesquisadores escrevem sobre fatos e eventos é sempre uma tentativa e, nesse sentido, estará sempre aberto a revisões. Foi assim que, ao apresentar sua narrativa através da dissertação de mestrado, em trocas com outros pesquisadores, a professora Atíria reviu posições sobre a sequência didática que havia proposto a seus alunos, que destacamos em sua escrita, a seguir:

Observa-se que as categorias escolhidas pelos alunos poderiam apresentar intersecções entre si (um mesmo aluno poderia ter várias dessas características), porém ficou esclarecido que eles optaram por uma única qualidade que fosse a mais representativa de sua auto-percepção, ou seja, aquela que mais bem representava sua pessoa. Eles também não escolheram, durante o processo, variáveis quantitativas que pudessem caracterizar a classe. Esse foi um lapso da professora-pesquisadora, que os poderia ter induzido a essa escolha e aproveitado tais dados quantitativos numa exploração futura para abordar conceitos da estatística. É, portanto, um aperfeiçoamento que poderá ser feito em futuras aplicações dessa sequência didática. 


\section{Considerações finais}

Ao pensar no desvelamento do que era sua própria cultura de aula de matemática, antes da experiência narrada pela professora Atíria (reflexão sobre a ação anterior), ao inserirse em um ambiente de formação continuada, ela passou também a pensar em mudanças para essas práticas (reflexão na ação), a fim de alcançar uma aprendizagem mais significativa de seus alunos e para tentar minimizar as tensões e conflitos que ocorriam em sua sala de aula. Assim, tendo como locus privilegiado a sua própria escola e como referência fundamental o seu saber docente (CANDAU, 2003, p. 143), após a execução da sequência didática proposta, Atíria constituiu outras narrativas sobre essa experiência, revendo reflexões anteriores (reflexão sobre a reflexão-na-ação).

Para Schön (2000, p. 36), a reflexão sobre a reflexão-na-ação é, dentre os três processos de reflexão que o professor deve fazer durante sua atividade cotidiana, o que mais contribui para a transformação e aperfeiçoamento da sua prática. Segundo esse autor, quando se reflete sobre a experiência anterior, consolida-se a compreensão de uma dificuldade ou desafio, ou cria-se uma solução melhor, ou mais geral para isso.

Contreras (2002, p. 106), ao discutir o saber prático, complementa que a ideia de profissional reflexivo desenvolvida por Schön trata justamente de dar conta da forma pela qual os profissionais enfrentam as situações que não se resolvem por meio de repertórios técnicos.

Analogamente, Pimenta e Lima (2004, p. 132) situam a reflexão como "elemento de emancipação humana, que é histórica, localizada e intencional. Trata-se de dar um sentido social à própria prática, mediando-a com a realidade vivida e analisando-a criticamente”.

Com a apresentação final dessas narrativas em sua dissertação de mestrado, com as trocas entre os pares pesquisadores, a professora alcançou novas reflexões em sua experiência, registrando-as para possibilidades de ações futuras com o uso da metodologia investigativa. Isto evidencia que a ação gerada com essa prática despertou-lhe possibilidades de novas aprendizagens e desenvolvimento profissional, através da perspectiva de futuras propostas de sequências didáticas significativas para os alunos, e que sejam factíveis para as salas de aula reais e complexas que encontramos na escola pública, na atualidade. Entretanto, gostaríamos de salientar que esse processo de construção de suas narrativas não foi linear e nem simples. As trocas com a formadora da universidade foram imprescindíveis para que essas narrativas fossem se constituindo, com idas e vindas, textos parciais pouco claros e que 
foram se delineando no processo inquiridor gerado na parceria, de ambos os lados. A análise das diferentes situações encontradas no percurso pessoal e profissional da professorapesquisadora constituiu a base das nossas conversas, gerando disponibilidades para ouvir o outro, trocar os textos e aceitar críticas às estruturas de reflexão que necessitavam ser aperfeiçoadas, para ir percebendo os cenários em que se movia, as causas das ocorrências, permitindo-lhe criar novas estratégias de atuação. Ao mesmo tempo, essas conversas se constituíram numa base cada vez mais sólida de conhecimentos, a partir do intercâmbio das aprendizagens da formadora e da professora-pesquisadora, relativamente à formação inicial desta última, seus conhecimentos tácitos e das práticas que ia desenvolvendo, ultrapassando dificuldades e bloqueios. O método narrativo serviu para proporcionar oportunidades de reflexão e de organização dessa reflexão, à medida que se foi confrontando com aspectos significativos do seu percurso profissional.

Assim, acreditamos que o uso de narrativas escritas pela professora Atíria, com registros que ocorreram em diversos momentos da ação pedagógica que estava sob investigação, proporcionou-lhe uma formação continuada que supera as concepções de formação clássica (CANDAU, 2003), uma vez que tomou em conta a realidade vivenciada pela professora em sua escola, as questões culturais escolares mais amplas (como as avaliações externas a que os seus alunos estavam submetidos e as expectativas de vida deles), o momento de seu desenvolvimento profissional, bem como seus saberes docentes e experiências anteriores. Sua narrativa se constituiu como o elo significativo entre a investigação que realizou sobre um momento de sua prática docente e a formação profissional, confrontando saberes anteriores com saberes novos, e outros saberes provenientes de outros modos de olhar, também personalizados, evidenciados pelo estudo das teorias sobre o ensino de Matemática com que teve contato.

\section{Referências}

ALARCÃO, I. Professores reflexivos em uma escola reflexiva. São Paulo: Cortez, 2003.

ANDRÉ, M. E. D. A. Etnografia da Prática Escolar. Campinas, SP: Papirus, 1995.

BROUSSEAU, G. Fondements et méthodes de la didactique dês mathématiques. Recherches em Didactique dês Mathématiques, Grenoble, v. 7, n. 2, p. 33-115, 1986.

CAETANO, A. P. Dilemas de professores. In: ESTRELA, M. T. (Org.). Viver e construir a profissão docente. Porto: Porto Editora, 1997, p. 191-221. 
CANDAU, V. M. F. Formação continuada de professores: tendências atuais. In: REALI, A. M. M. R.; MIZUKAMI, M. G. N. (Org.). Formação de professores: tendências atuais. 1. ed. São Carlos: EdUFSCar, 2003. p. 139-152.

CÂNDIDO, P. Comunicação em matemática. In: SMOLE, K. S.; DINIZ, M. I. (Org.). Ler, escrever e resolver problemas: habilidades básicas para aprender matemática. Porto Alegre: Artmed, 2001. p. $15-28$

CEZARI, V. G. F.; GRANDO, R. C. Cultura de aula de matemática presente nas narrativas de formação por professores do ensino fundamental. Horizontes, Belo Horizonte, v. 26, n. 1, p. 89-96, jan./jun. 2008.

CONTRERAS, J. A autonomia de professores. São Paulo: Cortez, 2002.

DAMICO, A. Uma investigação sobre a formação inicial de professores de matemática para o ensino de números racionais no ensino fundamental. 2007. 313 f. Tese (Doutorado em Educação Matemática) - Programa de Estudos Pós-Graduados em Educação Matemática, Pontifícia Universidade Católica de São Paulo, São Paulo, 2007. Disponível em: <http://www.sapientia.pucsp.br//tde_arquivos/13/TDE-2007-10-11T13:29:15Z4149/Publico/Alecio\%20Damico.pdf >. Acesso em: 10 jan. 2012.

FIORENTINI, D.; MIORIM, M. A. (Org.). Por trás da porta, que matemática acontece? Campinas: Editora Gráfica FE/UNICAMP - CEMPEM, 2001.

FREITAS, M. T. M.; FIORENTINI, D. As possibilidades formativas e investigativas da narrativa em educação matemática. Horizontes, Itatiba, v. 25, n. 1, p. 63-71, jan./jun. 2007.

GALVÃO, C. Narrativas em Educação. Ciência \& Educação, Bauru, v. 11, n. 2, p. 327-345, ago. 2005.

GARNICA, A. V. M. Analisando imagens: um ensaio sobre a criação de fontes narrativas para compreender os Grupos Escolares. Bolema, Rio Claro, v. 23, n. 35, p. 75-100, abr. 2010.

LARROSA, J. Literatura, experiência e formação. In: COSTA, M. V. (Org.). Caminhos investigativos: novos olhares na pesquisa em educação. Porto Alegre: Mediação, 1996. p.133-160.

LIBÂNEO, J. C. Reflexividade e formação de professores: outra oscilação do pensamento pedagógico brasileiro? In: PIMENTA, S. G.; GHEDIN, E. (Org.). Professor reflexivo no Brasil: gênese e crítica de um conceito. São Paulo: Cortez, 2002. p. 53-79.

PIMENTA, S. G. Professor reflexivo: construindo uma crítica. In: PIMENTA, S. G.; GHEDIN, E. (Org.). Professor reflexivo no Brasil: gênese e crítica de um conceito. São Paulo: Cortez, 2002. p. 1752.

PIMENTA, S. G; LIMA, M. S. L. Estágio e docência. São Paulo: Cortez, 2004.

PINTO, N. B. O Erro como Estratégia Didática. Curitiba: Papirus, 2000.

PONTE, J. P. da; BROCARDO, J.; OLIVEIRA, H. M. Investigações Matemáticas na Sala de Aula. Belo Horizonte: Autêntica, 2003.

RIESSMAN, C. Narrative analysis. California: Sage, 1993. 
SÃO PAUlO (Estado), Secretaria da Educação. Caderno do Aluno. Matemática - $\mathbf{7}^{\mathbf{0}}$ ano. São Paulo: IMESP, v. 1, 2, 3 e 4, 2008a.

SÃO PAUlO (Estado), Secretaria da Educação. Proposta Curricular do Estado de São Paulo. São Paulo: SE, 2008b.

SÃO PAULO (Estado), Secretaria da Educação. Relatório Pedagógico de Matemática - SARESP 2011. São Paulo: SE, 2012.

SAVIANI, D. Educação: do senso comum à consciência filosófica. Campinas: Autores Associados, 2000.

SCHÖN, D. A. Formar professores como profissionais reflexivos. In: NÓVOA, A. (Org.). Os professores e sua formação. Lisboa: Dom Quixote, 1992. p. 77-91.

SCHÖN, D. A. Educando o profissional reflexivo: um novo design para o ensino e a aprendizagem. Porto Alegre: Artmed, 2000.

SHULMAN, L. S. Those who understand: knowledge growth in teaching. Educational Researcher, Washington, v. 15, n. 2, p. 4-14, Fev. 1986.

TARDIFF, M. Saberes docentes e formação profissional. Petrópolis: Vozes, 2002.

ZEICHNER, Kenneth M. A formação reflexiva de professores: idéias e práticas. Lisboa: EDUCA, 1993. 